Folia Hort. 32(1) (2020): 1-9

DOI: 10.2478/fhort-2020-0001
Published by the Polish Society for Horticultural Science since 1989

\title{
An efficient protocol for Cistus crispus L. (Cistaceae) micropropagation
}

\author{
Sergio Saia ${ }^{1,2, * \odot, ~ A n t o n i o ~ G i o v i n o ~}{ }^{2 \odot}$ \\ ${ }^{1}$ Council for Agricultural Research and Economics (CREA) - \\ Research Centre for Cereal and Industrial Crops (CREA-CI), \\ S.S. 11 per Torino, $\mathrm{km} 2.5-13100$ Vercelli, Italy \\ ${ }^{2}$ Council for Agricultural Research and Economics (CREA) - \\ Research Centre for Plant Protection and Certification (CREA-DC),

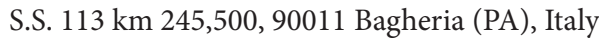

\begin{abstract}
Cistus crispus (Cistaceae) is a species adapted to arid and semi-arid conditions, and it has ornamental and medicinal uses. In Italy, native populations of C. crispus are threatened by the collection due to the low number of individuals in the populations, anthropogenic pressure, and the changing environmental condition that enhance other more aggressive and hybridisable Cistus species. Here, we set up the variables for its micropropagation protocols to achieve a high number of plants per unit time. Various steps of the micropropagation protocol were modulated, including various sodium hypochlorite concentrations (CHCs) and time of sterilisation. The efficiency of the protocol maximised at $25 \mathrm{~min}$ sterilisation with $2.5 \% \mathrm{CHC}$ and decreasing explant vitality at increasing time and $\mathrm{CHC}$. Both shoot proliferation and root emissions were maximised at $1.78 \mu \mathrm{M} \mathrm{N}$-6-benzyladenine (BA) in the growing medium, with up to 5.4 explants per cycle, with 5.8 roots per explant, and 84 healthy explants. Kinetin stimulated further the axillary root proliferation more than dimethylallylamino purine or BA. Lastly, the application of indole acetic acid increased root emissions during the acclimation stage more than the application of indole butyric acid, and this occurred irrespective of their concentrations, up to $2.0 \mu \mathrm{g} \cdot \mathrm{g}^{-1}$. These results can foster the use of $C$. crispus as an ornamental species, for xeriscaping or for the extraction of its secondary compounds, which have various industrial uses. These results can also have an indirect implication for the conservation of the species by reducing the collection for ornamental purposes from its natural population.
\end{abstract}

Keywords: biotechnology, conservation, Mediterranean maquis, plant hormones, rockrose

\section{Abbreviations:}

2iP, dimethylallylamino purine; BA, benzylaminopurine; c.p., coefficient of proliferation; $C_{\mathrm{GR}}$, concentration of each rooting hormones (IAA or IBA); CHC, hypochlorite concentration; GR, growth regulators; h.e., percentage of healthy explants; IAA, indole acetic acid; IBA, indole butyric acid; Kin, kinetin; MS, Murashige and Skoog; MW, molecular weight; n.r., number of roots; RBD, randomised block design; TS, time of sterilisation.

\section{INTRODUCTION}

Mediterranean, arid, and semi-arid areas are important centres of biodiversity (Giovino et al., 2016) and can host unique plant species with crucial roles in such fragile ecosystems (Giovino et al., 2014). However, due to a high anthropogenic pressure and climate change, the resilience of these ecosystems decreases. This also caused by the expansion of alien, often aggressive, species (from either plants or animals), 
which directly or indirectly menace many native taxa, especially the endemic ones (Badalamenti, 2016; Brundu, 2013; Giovino et al., 2016). Cistus crispus L. is a western Mediterranean species typical of the thermo-Mediterranean zone. It is a medium-sized, evergreen shrub with plant height usually up to approximately $100 \mathrm{~cm}$. This species has various uses including its application as an ornamental and/ or medicinal plant, whose extract can have strong fungicidal/fungistatic effects (Bouyahya et al., 2018), or it can be used for xeriscaping and recolonisation of fragile environments (Batista et al., 2017; GómezZotano et al., 2017), where it also plays an important role for feeding bees (Ortiz, 1994). C. crispus has been classified as endangered in the Red Data Book of plants of Italy (Conti et al., 1992). In Italy, it is presumed to be native only in Sicily (Rizzotto, 1979), where it is very rare and localised (Bartolo et al., 1994). C. crispus has also been reported as a casual xenophyte in Liguria (Gentile and Gentile, 1994). It has been shown that Cistus species have a polyphyletic genetic structure and an insular diversification (Carlier et al., 2008; Guzmán and Vargas, 2005). Indeed differences were frequently found, in various species, between genotypes from Sicily and others from North Africa despite the share of similar soils (Barrajõn-Catalán et al., 2011; Giovino et al., 2015c; Said et al., 2016). However, in the Sicilian area, the environment is subjected to strong anthropogenic pressure. Such a condition does not allow $C$. crispus to easily renew and can have drawback for repopulating the plant community, especially if considering that such a species is also collected for ornamental purposes. This calls for a genetic and environmental protection of this species through adoption of ad hoc conservation practices, especially if considering its rarity and that Cistus species can undergo hybridisation with non-native species from the same genus (Navarro-Cano et al., 2017). Such measures of propagation should rely on both sexuate and asexuate reproduction methods to conserve the intraspecific variability and increase the number of individuals available for ornamental purposes and to recolonise the native areas. However, orthodox seeds, such as those of Cistus (Papafotiou et al., 2000; Scuderi et al., 2010), frequently have reproduction strategies, including an asynchronous germination, which reduces the efficacy of sowing to rapidly recolonise native areas. This often occurs for other species whose embryo has a maturation stage after seed dispersal from the same areas (Giovino et al., 2015b, 2015d). In addition, it hampers to address the use of this species as ornamental or medicinal plant or for xeriscaping, given its aesthetic value, high resistance to stresses, and content in secondary compounds with potential industrial uses, as showed for other species (Giovino et al., 2014; Kubica et al., 2017). In addition, Cistus spp. showed own rooting from cuttings (Papafotiou et al., 2000), which hampers its uses.
In vitro propagation has important applications for both the protection of endangered species and genotype conservation (Preil, 2003; Rout and Jain, 2004). Micropropagation by direct organogenesis of endangered species is a valid method in comparison with traditional propagation practices to avoid depletion of natural populations, which further implies the disturbance of the native sites for seed collection and a high amount of nursery/greenhouse/field work for plant establishment.

The aim of this study was thus setting a micropropagation protocol for this species. In particular, we tested the response of explant proliferation of various protocols of explant sterilisation under micropropagation and rooting after and hormone (i.e., growth regulators $(\mathrm{GR}))$ treatments at both the micropropagation stage and rooting stage.

\section{MATERIALS AND METHODS}

\section{Culture initiation}

The propagation material was collected from a plant from the population of Colle San Rizzo (Messina province, Sicily, Italy). Explants used were 4- to 5-mmlong apical sprout with two verticils and a bud at its base, coming from primary and secondary branches (Ruta and Morone-Fortunato, 2010) with no evident damages or pathogenic attacks. The explants were collected from actively growing upper branches during the year of collection. The micropropagation procedure was performed under horizontal laminar flow after device sterilisation under ultraviolet-C radiation at $15 \mathrm{~W}$ per $30 \mathrm{~min}$.

\section{Effect of sodium hypochlorite concentration $(\mathrm{CHC})$ and time of sterilisation (TS)}

Explants were sterilised by washing in water and then in ethanol-water solution (70:30 v/v, Sigma-Aldrich), after which sterilisation treatments were sodium hypochlorite ( $5 \%$ active chlorine, w/v, Sigma-Aldrich) concentration $2.0 \%, 2.5 \%, 3.0 \%$, or $3.5 \%$ (in water by $\mathrm{v} / \mathrm{v}$, mixed at $25^{\circ} \mathrm{C}$ and atmospheric pressure) where 20 drops $\cdot 1^{-1}$ of Tween 20 (Sigma-Aldrich) were added. Sterilisation treatments lasted 25 or $35 \mathrm{~min}$. Soon after sterilisation, explants were rinsed various times in sterile distilled water. The explants described earlier were placed in Magenta ${ }^{\mathrm{TM}}$ B-cap jars (Sigma-Aldrich) filled with $50 \mathrm{~mL}$ of a Murashige and Skoog (MS) macronutrient medium (Murashige and Skoog, 1962) (Sigma-Aldrich), Nitsch and Nitsch micronutrients (Nitsch and Nitsch, 1969), Fe-EDTA (30 $\left.\mathrm{mg} \cdot \mathrm{1}^{-1}\right)$, thiamine $\left(0.4 \mathrm{mg} \cdot 1^{-1}\right)$, myoinositol $\left(100 \mathrm{mg} \cdot 1^{-1}\right)$, agar (Bacteriological Agar, No. 1 Oxoid; $8 \mathrm{~g} \cdot 1^{-1}$ ), and sucrose $\left(30 \mathrm{~g} \cdot \mathrm{l}^{-1}\right)$. The experimental unit was a jar with 20 explants (Figure 1A). Each treatment was replicated four times, kept at $24^{\circ} \mathrm{C} \pm 1{ }^{\circ} \mathrm{C}$ under $50 \mu \mathrm{mol} \cdot \mathrm{m}^{-2} \cdot \mathrm{s}^{-1}$ light by cool-white fluorescent tubes (Osram), and a $16 \mathrm{~h} / 8 \mathrm{~h}$ day-night photoperiod. The experiment was 

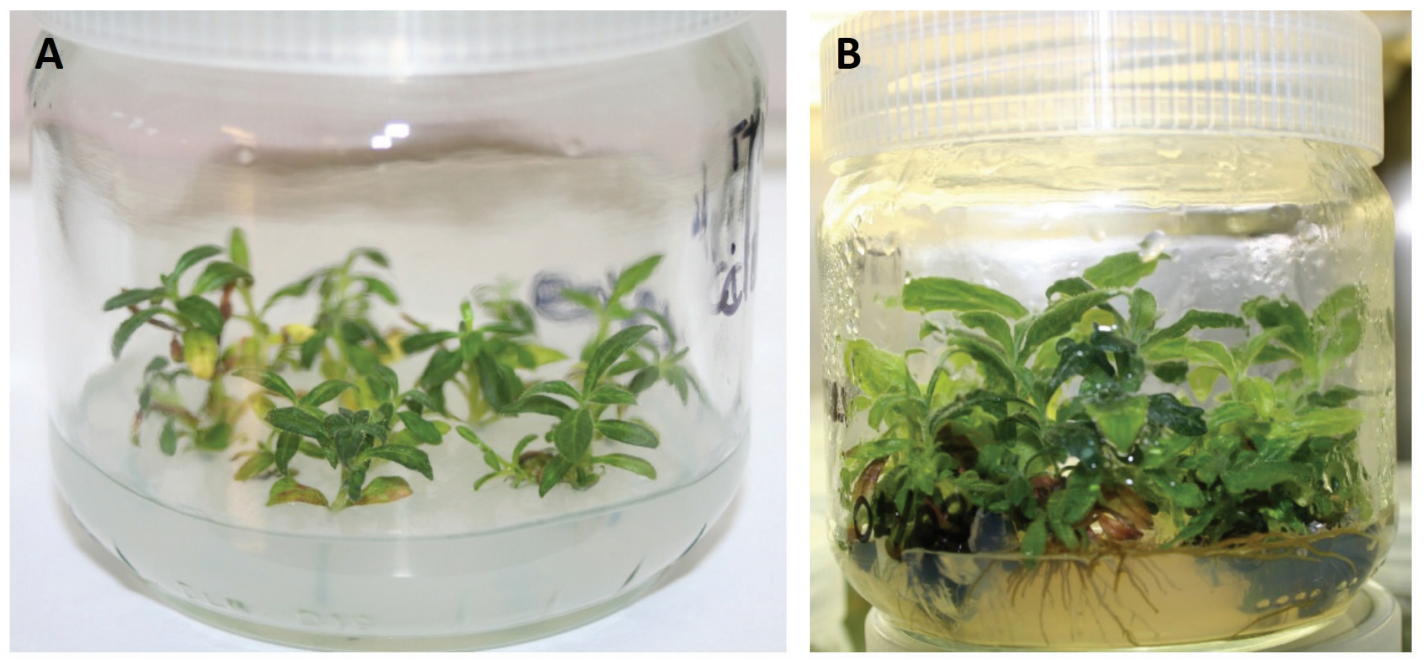

Figure 1. (A) Experimental unit at the beginning of the experiment: apical sprout from primary and secondary branches. (B) Experimental unit at the time of establishment in vitro.

arranged according to a randomised block design (RBD). After 4 weeks, percentage of sterile explants and their vitality were computed as number of vital explants above the number of sterile explants. An explant was considered vital when free of browning or necrosis.

\section{Propagation}

\section{Effect of benzylaminopurine (BA) concentration}

Shoot clumps obtained during initiation (4 weeks after initiation) from the treatment with the highest percentage of vital explants were used to test the proliferation rate after increasing concentration of BA (Sigma-Aldrich) in the propagation. Explants were placed in jars filled with an MS medium as earlier and supplemented with $0.88,1.78,3.55,7.45 \mathrm{mM}$ BA or were untreated (referred as 0 ). The medium was solidified with agar as earlier. Explants were maintained as in the previous experiment. The experimental design was a RBD with four replicates. One subculture lasted for 4 weeks. After 10 subcultures, proliferation rate, (computed as number of shoots per explant), number of adventitious roots per explant, and percentage of healthy explants (referred as c.p., n.r., and h.e., respectively) were computed. An explant was considered healthy when it was free of browning or necrosis and leaves appeared turgid.

\section{Effect of kind (BA, kinetin (Kin), dimethylallylamino purine $(2 i P))$ and concentration of cytokinins (CYTs)}

Stem explants (15 $\mathrm{mm}$ long, two-node sections) obtained from in vitro plantlets of Cistus multiplied on a MS medium as earlier (Sigma-Aldrich), 1.5 $\mu \mathrm{M}$ indole butyric acid (IBA; Sigma-Aldrich), and agar as earlier and $\mathrm{pH}$ set to 5.7 were used for the experiment. The experimental unit was a jar with 20 explants. The stock of shoot cultures was increased by sub-culturing every 4 weeks on a complete MS medium. Experimental design was a RBD replicated four times. The effect of three CYTs was investigated, BA (molecular weight (MW): 225.25), Kin (MW: 215.21), and 2iP (MW: 203.24) (Sigma-Aldrich), which were used in the following concentrations: $0.3,0.6$, and $1.2 \mu \mathrm{g} \cdot \mathrm{g}^{-1}$, respectively, and an untreated control referred as 0.0 . After 5 weeks, the coefficient of shoot proliferation was calculated.

\section{Rooting}

\section{Effect of auxin}

Stem explants ( 15-mm-long, two-node sections) were obtained from in vitro plantlets of Cistus multiplied on a MS medium as earlier, $1.5 \mathrm{mM}$ IBA and agar as earlier, and $\mathrm{pH}$ set to 5.7 in the present experiment. The experimental unit was a jar with 15 stem explants $\sim 150$-mm-long, two-node sections. Treatments were as follows: application of rooting hormone (RH; GR): indole acetic acid (IAA) or IBA (Sigma-Aldrich) and concentration $\left(C_{\mathrm{GR}}\right)$ of each of these RHs: 0.5, 1.0, and $2.0 \mathrm{mg}$ of compound $\mathrm{g}^{-1}$ medium and an untreated control referred as 0.0 . After 5 weeks, root number per cutting was counted.

\section{Acclimatization}

Plantlets were transferred to Jiffy ${ }^{\circledR}$ pots, and plant acclimatisation was evaluated after 4 weeks in a heated greenhouse according to Lazzara et al. (2017).

\section{Computations and statistical analysis}

Before starting the analysis, all data were checked for normality by means of the Shapiro-Wilk test (proc. Univariate, SAS/STAT 9.2, SAS Institute Inc., Cary, NC, USA) since the number of samples was lower than 2000. All data had a normal distribution, including 
those of ratios or percentages, and thus were analysed with no transformation.

Data from each experiment were subjected to analysis of variance by means of the GLIMMIX procedure in SAS/STAT 9.2 environment, according to the experimental design. Differences among mean values of treatments with more than two statistical levels and interactions were compared by applying Tukey's " $t$-grouping" at the $5 \%$ probability level to the LSMEANS estimate. See the supplementary material in Saia et al. (2020) for both a description of the procedure and the SAS package model applied.

\section{Sterile explants}

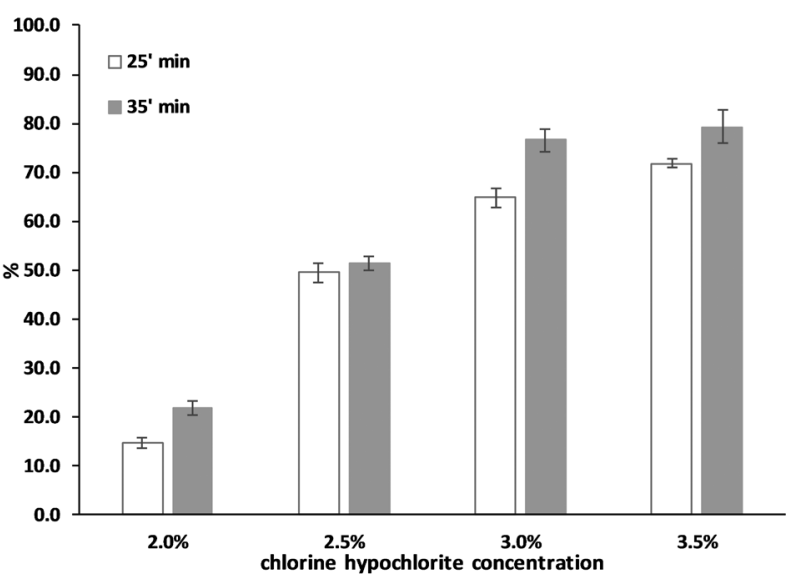

\section{RESULTS}

\section{Culture initiation}

Percentage of sterile explants (Figure 2) increased by $32 \%$ and $20 \%$ when increasing $\mathrm{CHC}$ from $2.0 \%$ to $2.5 \%$ and $2.5 \%$ to $3.0 \%$, respectively, with no differences between $3.0 \%$ and $3.5 \%$. Similarly, increasing TS raised the sterile explants by $14 \%$, with no $\mathrm{CHC} \times \mathrm{TS}$ interaction.

Percentage of vital explants (Figure 2) decreased by $38 \%$, on average, when TS increased from 25 to $35 \mathrm{~min}$, and such a difference mostly occurred at $\mathrm{CHC}$ higher

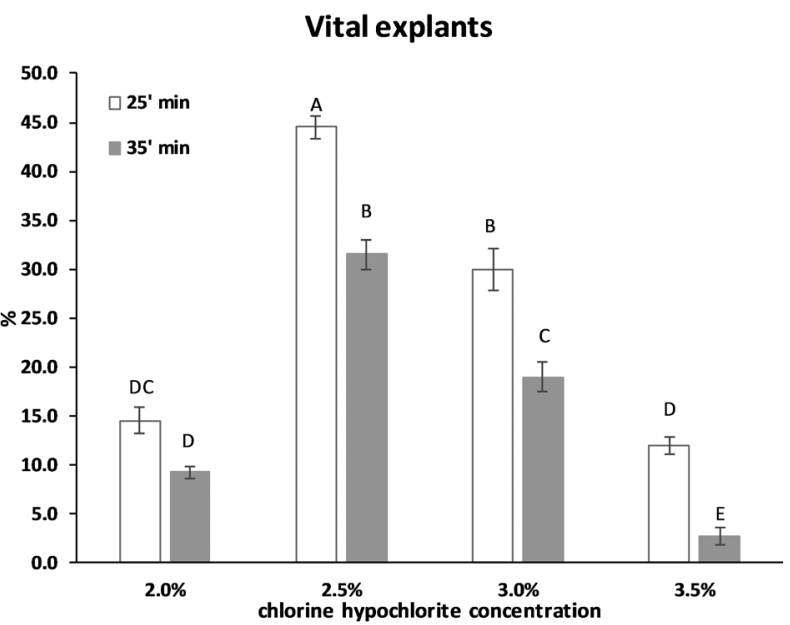

Figure 2. Percentage of sterile (left panel) and vital explants (right panel) of Cistus crispus at increasing sodium hypochlorite concentration (CHC) and time of sterilisation (TS). Data are values of mean \pm standard error. For sterile explants, CHC: $F=31.2, p<0.001$; TS: $F=423.6, p<0.001$; and $\mathrm{CHC} \times \mathrm{TS}: F=2.5, p=0.088$. For vital explants, CHC: $F=135.2, p<0.001$; TS: $F=276.7, p<0.001$; and $\mathrm{CHC} \times \mathrm{TS}: F=4.0, p=0.022$. When $\mathrm{CHC} \times \mathrm{TS}$ was significant, treatments were separated by $t$-grouping of the LSMEANS estimate. Treatments with a letter in common are not different at $t_{0.05}$-grouping.

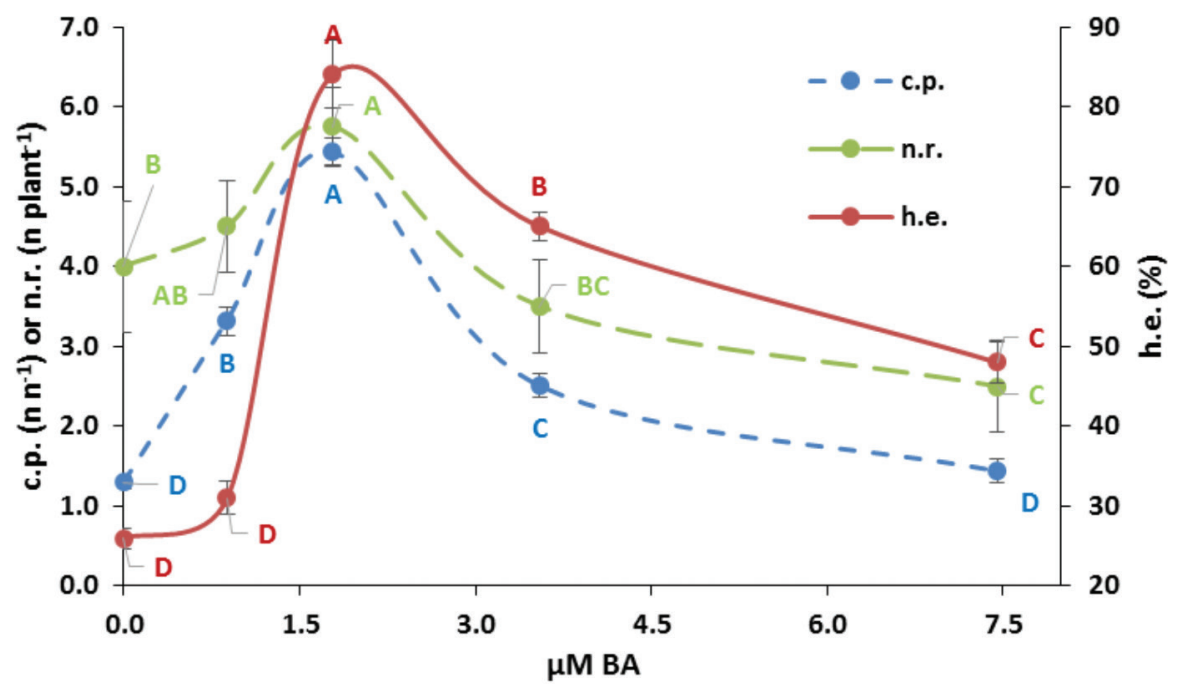

Figure 3. Coefficient of proliferation (c.p.), number of root (n.r.), and percentage of healthy explants (h.e.) of Cistus crispus cuttings at increasing benzylaminopurine (BA) concentration. Data are values of mean \pm standard error. c.p.: $F=652.3, p<0.001$; n.r.: $F=15.1, p<0.001$; and h.e.: $F=314.3, p<0.001$. Within each variable, treatments with a letter in common are not different at $p>0.05$ according to the Tukey's test applied to the LSMEANS estimates' differences. 


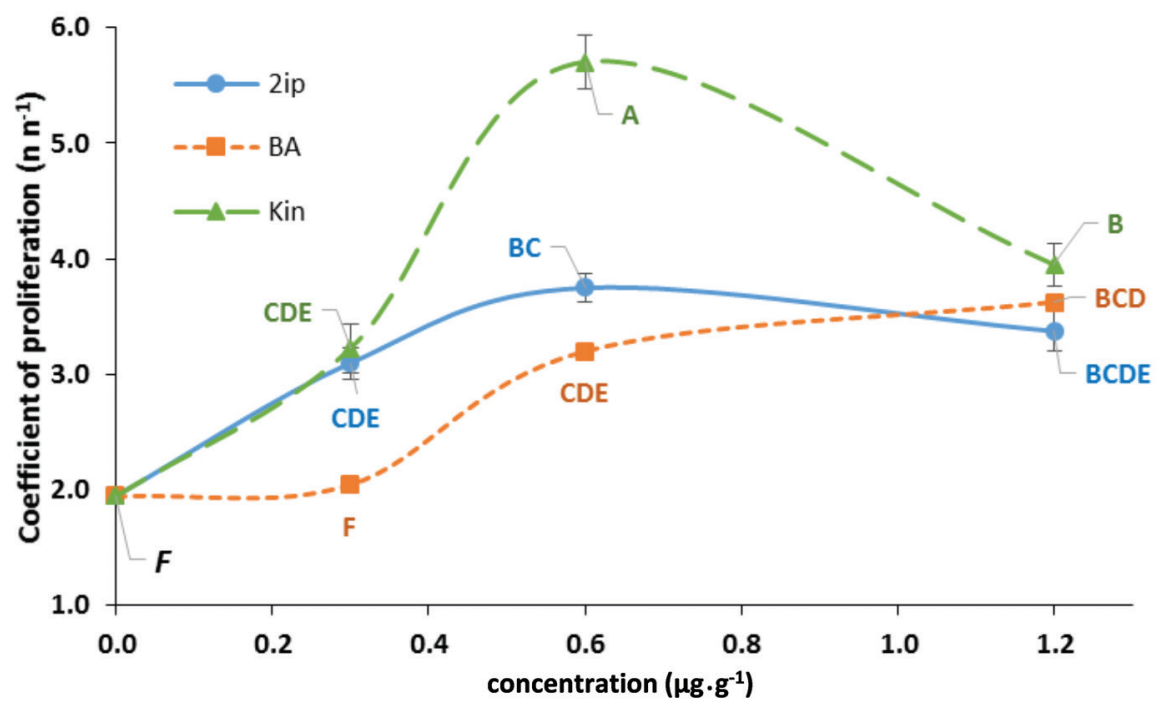

Figure 4. Coefficient of axillary shoot proliferation of Cistus crispus microcuttings at increasing concentration $\left(C_{\mathrm{CYT}}\right)$ of cytokinins (CYTs): benzylaminopurine (BA), kinetin (Kin), or dimethylallylamino purine (2iP). Data are values of mean \pm standard error. CYT: $F=67.3, p<0.001 ; C_{\mathrm{CYT}}: F=75.2, p<0.001$; and $C_{\mathrm{CYT}}(\mathrm{CYT}): F=20.6, p<0.001$. DFnum and DFden of $C_{\mathrm{CYT}}(\mathrm{CYT})$ were 4 and 27, respectively. Treatments with a letter in common are not different at $p>0.05$ according to the Tukey's test applied to the LSMEANS estimates' differences.

than $2.0 \%$, although with a scarce interaction. Varying $\mathrm{CHC}$ resulted in a variation of the percentage of vital explants, with a boost from $2.0 \%$ to $2.5 \%$ and then a constant decrease while further increasing $\mathrm{CHC}$ to values close to 0 .

\section{Propagation}

\section{Effect of $B A$ concentration}

Coefficient of proliferation (c.p.), number of roots (n.r.), and percentage of healthy explants (h.e.) peaked at $1.78 \mathrm{mM}$ BA concentration and decreased at higher BA concentrations (Figures 3 and 1B, respectively). In particular, h.e. variation was particularly evident at increasing BA from 0.88 to $1.78 \mu \mathrm{M}$, whereas they were scarce when adding $0.88 \mu \mathrm{M}$ BA compared to the untreated control. The decrease in these variables was almost constant when increasing BA from 1.78 to $7.45 \mu \mathrm{M}$.

\section{Effect of kind (BA, Kin, 2iP) and concentration of CYTs}

Application of GR increased by $5.1 \%$ to $192.3 \%$ axillary shoot proliferation. When applying to $0.3 \mu \mathrm{g} \cdot \mathrm{g}^{-1}$ of $2 \mathrm{iP}$ and Kin, axillary shoot proliferation increased compared to the untreated control, whereas no differences were found for BA (Figure 4).

A further increase from 0.3 to $0.6 \mu \mathrm{g} \cdot \mathrm{g}^{-1} \mathrm{GR}$ increased axillary shoot proliferation of $C$. crispus in $\mathrm{BA}$ and Kin, but not in 2iP. An additional increase in the GR concentration from 0.6 to $1.2 \mu \mathrm{g} \cdot \mathrm{g}^{-1}$ did not affect axillary shoot proliferation in $2 \mathrm{iP}$ and BA and decreased it in Kin, which showed similar coefficients compared to the other GR.

\section{Rooting}

\section{Effect of auxin}

Application of IBA promoted root emission 26.5\% less than IAA (Figure 5) and resulted in no promotion at $2.0 \mu \mathrm{g} \cdot \mathrm{g}^{-1}$. RH increased root number especially at $0.5 \mu \mathrm{g} \cdot \mathrm{g}^{-1}(+100 \%$ and $+50 \%$ in IAA and IBA, respectively, compared to the untreated control).

Acclimatisation in the greenhouse during 4 weeks was complete $(100 \%)$ irrespective of the treatments applied in Experiment 2. Data were thus not statistically processed.

\section{DISCUSSION}

Micropropagation for conservation purposes of other endangered Cistus species has been proposed with contrasting results (Aregui et al., 1997; Gatti et al., 2004; López-Orenes et al., 2013; M'Kada et al., 1991). In the present experiment, we obtained a coefficient of proliferation of 1.3-2.0 when no GR were applied, which is similar or higher than the values found in Cistus heterophyllus (López-Orenes et al., 2013). Such a rate increased by $2.9-4.2$ fold when the most suitable concentration of GR was applied. These results were better than those observed in C. $\times$ purpureus (M'Kada et al., 1991), Cistus clusii (Ruta and Morone-Fortunato, 2010), or Cistus ladanifer (Boukili et al., 2017) and similar to those found in Cistus salvifolius (Louro et al., 2017), where higher hypochlorite concentration was used than that in the present study, but lower than that in other Cistus species obtained by micropropagated plantlets from callus (Madesis et al., 2011) or seeds (Zygomala et al., 2003). Zygomala et al. (2003) also found a higher percentage of vital explants than the 


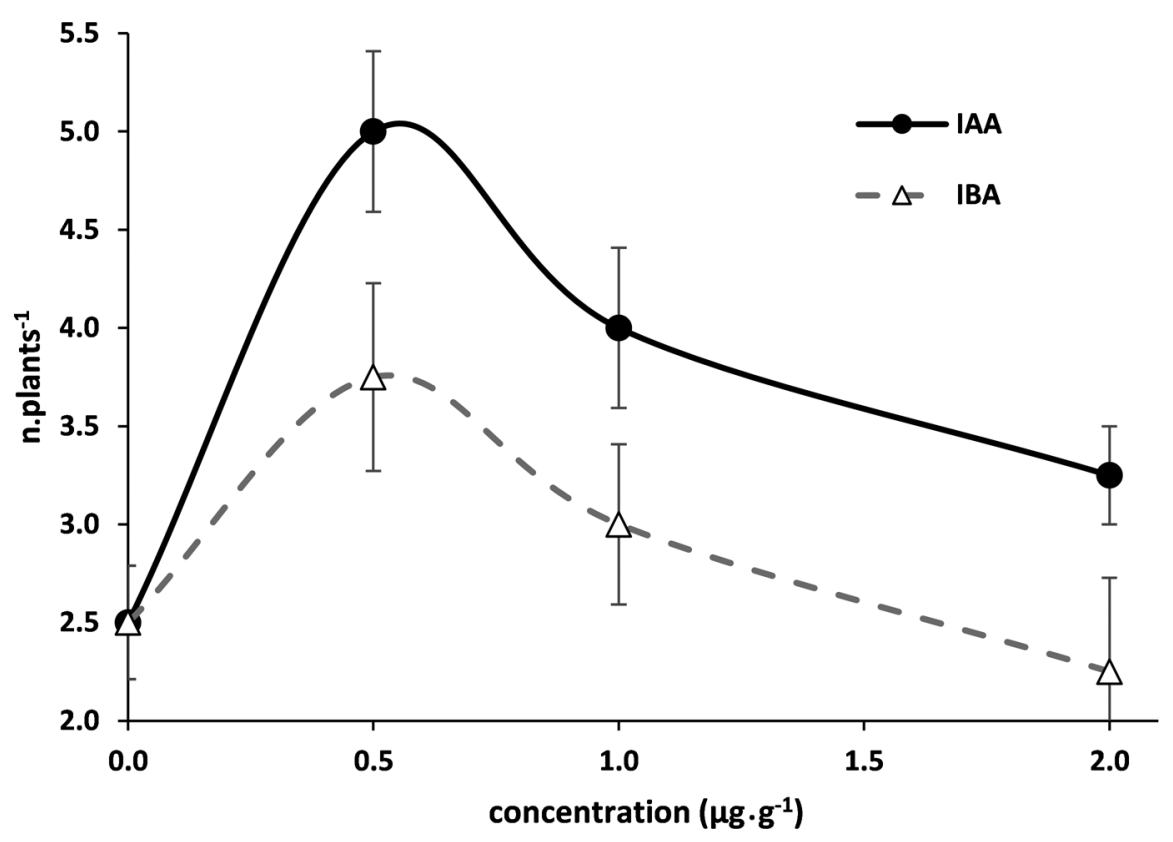

Figure 5. Root number of Cistus crispus microcuttings at increasing concentration $\left(C_{\mathrm{AUX}}\right)$ of auxin (AUX): indole acetic acid (IAA) or indole butyric acid (IBA). Data are values of mean \pm standard error. AUX: $F=11.4, p=0.003$; $C_{\mathrm{AUX}}: F=8.6, p=0.002 ; C_{\mathrm{AUX}}(\mathrm{AUX}): F=0.007, p=0.935$. DFnum and DFden of $C_{\mathrm{AUX}}$ (AUX) were 2 and 18 , respectively.

present study. Differences in our results compared to those of Madesis et al. (2011) and Zygomala et al. (2003) can be due to both the different genotypes tested and ability of the treatment to sterilise the explant without harming its vitality. In particular, the explant vitality may also depend on the explant antioxidant response to the treatments applied and kind of pathogens in the explant (Ortuño et al., 2018), age of the starting material or position in the mother plant, relative response to nutrients and light (Martínez-Estrada et al., 2016; Mills, 2009; Yoo and Lee, 2017), and higher amount of $\mathrm{Na}^{+}$ used in Zygomala et al. (2003) compared to the present study. $\mathrm{Na}^{+}$concentration could have affected the $\mathrm{K}^{+} / \mathrm{Na}^{+}$ and $\mathrm{Ca}^{2+} / \mathrm{Na}^{+}$on the plant tissues and thus increased their antioxidant capacity. This latter trait can determine the outcome of the micropropagation (López-Orenes et al., 2013). Application of sodium hypochlorite to the explant resulted in a higher percentage of vital explants at the $2.5 \%$ concentration and at the time of exposure of $25 \mathrm{~min}$ compared to $35 \mathrm{~min}$. Interestingly, a longer time $(35 \mathrm{~min}$ ) of exposure with the same concentration did not consist of an increase in the percentage of vital explants. This implies that sterilisation of the explants also damaged some explant or bud traits. Coefficient of propagation was relatively high even when no CYTs or auxin was applied; thus, these changes could be due to the hormones' ratios in the explant, as suggested by the low differences in root numbers at increasing BA or coefficient of proliferation at increasing BA or 2ip, whose activity compared to Kin reported to be lower (Ortuño et al., 2018). In this work, the application of low concentration of CYT regulators increased the root number less than auxin (1.26-fold and 2.00-fold, respectively). This implies that concentration of auxin was likely impairing the micropropagation process in these explants. The present results agree with those found in C. clusii (Ruta and Morone-Fortunato, 2010), which also found a complete acclimatisation with two substrates when no mist was applied. Similarly, Pela et al. (2000) found that RHs reduced explant proliferation. Nonetheless, the present results could have also depended on the age of the mother plants and culture age, as shown in other species (Öncel and Erişen, 2017; Park et al., 2017) and on the specific response to any of the auxin used (Öncel and Erişen, 2017). For example, it was found that IBA can induce more roots than IAA or other plant hormones depending on the species (Jana et al., 2017; Ou et al., 2015) and that differences between IBA and IAA can depend on the substrate (Sedlák and Paprštein, 2011). Lastly, it was shown that genotypic response to IBA and other hormones can vary even within species and depending on the micropropagation conditions (Jamwal et al., 2016; Venkatasalam et al., 2015).

The increase in the number of roots found in the present work has implication for both the production of Cistus as an ornamental species and for conservation in the native site, if considering that $C$. crispus has a root system less expanded than other Cistus species and a lower growth rate (Silva et al., 2003; Silva et al., 2002; Latorre et al., 2007).

\section{CONCLUSIONS}

The study of the propagation of endangered plants is oriented toward methods, such as micropropagation, 
that can limit further impoverishment of rare plant material (Fay, 1992; Giovino et al., 2015a; Manokari and Shekhawat, 2018). In conclusion, the protocol used here showed very high performance in number of plants obtained per unit time and could be used for various aims, including its mass production with low costs or the increase in the presence of C. crispus in the natural environment. This could also reduce the genetic introgression from other similar species that can hybridise with C. crispus. This is particularly important when considering that diversification in Cistus depends on the geographical isolation between the species (Fernández-Mazuecos and Vargas, 2011; Navarro-Cano et al., 2017).

\section{ACKNOWLEDGEMENTS}

The authors are grateful to Dr. Marcello Airò and Mr. Gaetano Giardina for kind help in growth chamber experiments and Mr. Giuseppe Farruggia for help during collection of plant materials. The authors also wish to thank the reviewers and editor for the valuable comments and suggestions that improved this manuscript.

\section{FUNDING}

This work was supported by the project "Risorse tecniche e genetiche per il florovivaismo (FLO.RIS), Section: Realizzazione di protocolli di propagazione di piante ornamentali in ambiente mediterraneo per il verde d'arredo (microarredo)", which was funded by the Italian Ministry of Agricultural, Food and Forestry Policies (MiPAAF).

\section{AUTHOR CONTRIBUTIONS}

A.G. performed the experiment. S.S. performed statistical analysis and wrote the manuscript. S.S. and A.G. conceived the experiment and approved the final version of the manuscript.

\section{CONFLICT OF INTEREST}

The authors declare no conflict of interest.

\section{REFERENCES}

Aregui, J. M., Juarez, J., Laguna, E., Reyna, S., And Navarro, L. (1997). Micropropagation of Cistus heterophyllus. An example of tissue culture application. Conservation of endangered species. Agricola Vergel (Espana), 186, 363-365.

Badalamenti, E., Militello, M., La Mantia, T., And Gugliuzza, G. (2016). Seedling growth of a native (Ampelodesmos mauritanicus) and an exotic (Pennisetum setaceum) grass. Acta Oecologica, 77, 37-42.

Barrajõn-Catalán, E., Fernández-Arroyo, S., Roldán, C., Guillén, E., Saura, D., Segura-Carretero, A., And Micol, V. (2011). A systematic study of the polyphenolic composition of aqueous extracts deriving from several Cistus genus species: Evolutionary relationship. Phytochemical Analysis, 22(4), 303-312.

Bartolo, G., Brullo, S., and Pulvirenti, S. (1994). Considerazioni fitosociologiche sulla vegetazione a Cistus crispus del territorio di Messina (Sicilia nordorientale). Bollettino delle sedute della Accademia gioenia di scienze naturali in Catania, 27(346), 409-414.

Batista, M. J., Gonzalez-Fernandez, O., Abreu, M. M., Queralt, I., and Carvalho, M. L. (2017). Pioneer Mediterranean shrub species revegetating soils developed on mining soils/spoils. Land Degradation \& Development, 28(2), 718-730.

Boukili, M., Chakir, S., Haloui, Z., and EchChgadda, G. (2017). Rapid in vitro multiplication of Cistus ladanifer L. var. maculates Dun. Journal of Materials and Environmental Sciences, 8(5), 1489-1494.

Bouyahya, A., Bakri, Y., Et-Touys, A., Assemian, I. C. C., Abrini, J., AND DAKKA, N. (2018). In vitro antiproliferative activity of selected medicinal plants from the North-West of Morocco on several cancer cell lines. European Journal of Integrative Medicine, 18, 23-29.

BRundu, G. (2013). Invasive alien plants in protected areas in Mediterranean Islands: Knowledge gaps and main threats. In L. C. Foxcroft, P. Pyšek, D. M. Richardson, and P. Genovesi (Eds), Plant invasions in protected areas (pp. 395-422). Dordrecht, Netherlands: Springer.

CArlier, J., LeitÃo, J., And Fonseca, F. (2008). Population genetic structure of Cistus ladanifer L. (Cistaceae) and genetic differentiation from co-occurring Cistus species. Plant Species Biology, 23(3), 141-151.

Conti, F., Manzi, A., And Pedrotti, F. (1992). Libro rosso delle Piante d'Italia. Roma: Ministero Ambiente, WWF Italia. SocietaBotanica Italiana.

FAY, M. F. (1992). Conservation of rare and endangered plants using in vitro methods. In Vitro Cellular \& Developmental Biology - Plant, 28(1), 1-4.

Fernández-Mazuecos, M., And Vargas, P. (2011). Genetically depauperate in the continent but rich in oceanic islands: Cistus monspeliensis (Cistaceae) in the Canary Islands. PLoS ONE, 6(2), e17172.

Gatti, E., Predieri, S., And Govoni, M. (2004). In vitro culture of autochthonous Mediterranean plants: Rockrose, curry plant, rosemary and lentisk [Cistus spp.; Helychrisum italicum (Roth) Don; Rosmarinus officinalis L.; Pistacia lentiscus L.]. Italus Hortus, 11(4), 135-137.

Gentile, S., And Gentile, A. (1994). Ricognizione floristica e note sulla vegetazione spontanea de la Mortola (Liguria occidentale). Fitosociologia, 27, 177-229.

Giovino, A., Domina, G., Bazan, G., Campisi, P., And Scibetta, S. (2015). Taxonomy and conservation of Pancratium maritimum (Amaryllidaceae) and 
relatives in the Central Mediterranean. Acta Botanica Gallica, 162(4), 289-299.

Giovino, A., Mammano, M. M. M., Gugliuzza, G., And SAIA, S. (2015). Germination pattern of Chamaerops humilis seed after short-time storage. Acta Horticulturae, 1099, 433-437.

Giovino, A., Marino, P., Domina, G., Rapisarda, P., RizzA, G., AND SAiA, S. (2015). Fatty acid composition of the seed lipids of Chamaerops humilis L. natural populations and its relation with the environment. Plant Biosystems - An International Journal Dealing with All Aspects of Plant Biology, 149(4), 767-776.

Giovino, A., Marino, P., Domina, G., Scialabba, A., Schicchi, R., Diliberto, G., Rizza, C., and Scibetta, S. (2016). Evaluation of the DNA barcoding approach to develop a reference data-set for the threatened flora of Sicily. Plant Biosystems - An International Journal Dealing with All Aspects of Plant Biology, 150(4), 631-640.

Giovino, A., Martinelli, F., And Saia, S. (2016). Rhynchophorus ferrugineus attack affects a group of compounds rather than rearranging Phoenix canariensis metabolic pathways. Journal of Integrative Plant Biology, 58(4), 388-396.

Giovino, A., Militello, M., Gugliuzza, G., and Saia, S. (2014). Adaptation of the tropical hybrid Euphorbia $\times$ lomi Rauh to the exposure to the Mediterranean temperature extremes. Urban Forestry \& Urban Greening, 13(4), 793-799.

Giovino, A., Scibetta, S., Saia, S., and Guarino, C. (2014). Genetic and morphologic diversity of European fan palm (Chamaerops humilis L.) populations from different environments from Sicily. Botanical Journal of the Linnean Society, 176(1), 66-81.

Giovino, A., Scibetta, S., Saia, S., and Ruffoni, B. (2015). Influence of seed treatment on germination pattern of Chamaerops humilis. Acta Horticulturae, 1099(1099), 427-432.

Gómez-Zotano, J., Olmedo-Cobo, J. A., and AriasGarcía, J. (2017). Mediterranean dune vegetation: conservation of a threatened ecosystem in southern Spain. Geografisk Tidsskrift-Danish Journal of Geography, 117(1), 36-52.

Guzmán, B., And Vargas, P. (2005). Systematics, character evolution, and biogeography of Cistus L. (Cistaceae) based on ITS, trnL-trnF, and matK sequences. Molecular Phylogenetics and Evolution, 37(3), 644-660.

Jamwal, M., Sharma, S., Jain, R. K., And Dalal, R. P. S. (2016). Development of in vitro propagation protocol and gus expression studies on Asiatic lily hybrids (Lilium spp.). Indian Journal of Horticulture, 73(2), 245.

JANA, ŠS., PAVla, Z., And Eloy FernándeZ, C. (2017). An efficient in vitro propagation protocol for snowdrop anemone (Anemone sylvestris L.). Horticultural Science, 44(4), 186-194.

Kubica, P., Szopa, A., And Ekiert, H. (2017). In vitro shoot cultures of pink rock-rose (Cistus $\times$ incanus $\mathrm{L}$.) as a potential source of phenolic compounds. Acta Societatis Botanicorum Poloniae, 86(4), 3563.

Latorre, A. V. P., Gavira, O., and Cabezudo, B. (2007). Ecomorphology and phenomorphology of Mediterranean heathlands (SW Iberian Peninsula). Phytocoenologia, 37(2), 239-268.

Lazzara, S., Militello, M., Carrubba, A., Napoli, E., AND SAIA, S. (2017). Arbuscular mycorrhizal fungi altered the hypericin, pseudohypericin, and hyperforin content in flowers of Hypericum perforatum grown under contrasting $\mathrm{P}$ availability in a highly organic substrate. Mycorrhiza, 27(4), 345-354.

López-Orenes, A., Ros-Marín, A. F., Ferrer, M. A., And Calderón, A. A. (2013). Antioxidant capacity as a marker for assessing the in vitro performance of the endangered Cistus heterophyllus. The Scientific World Journal, 2013, 176295, 1-10.

Louro, R., Peixe, A., And Santos-Silva, C. (2017). New insights on Cistus salviifolius L. Micropropagation, 6(3), 12-16.

M'Kada, J., Dorion, N., And Bigot, C. (1991). In vitro propagation of Cistus $\times$ purpureus Lam. Scientia Horticulturae, 46(1-2), 155-160.

Madesis, P., Konstantinidou, E., Tsaftaris, A., And Nianiou-Obeidat, I. (2011). Micropropagation and shoot regeneration of Cistus creticus ssp. creticus. Journal of Applied Pharmaceutical Science, 1(8), 54-58.

MANokari, M., And Shekhawat, M. S. (2018). Improved micropropagation and foliar micromorphological studies in Turnera ulmifolia L. - An important medicinal plant. Folia Horticulturae, 30(2), 283-294.

Martínez-Estrada, E., CaAmal-Velázquez, J. H., Morales-Ramos, V., and Bello-Bello, J. J. (2016). Light emitting diodes improve in vitro shoot multiplication and growth of Anthurium Andreanum lind. Propagation of Ornamental Plants, 16(1), 3-8.

Mills, D. (2009). Effect of sucrose application, minerals, and irradiance on the in vitro growth of Cistus incanus seedlings and plantlets. Biologia Plantarum, 53(3), 415-421.

Murashige, T., And Skoog, F. (1962). A revised medium for rapid growth and bio assays with tobacco tissue cultures. Physiologia Plantarum, 15(3), 473-497.

Navarro-Cano, J. A., Schwienbacher, E., SánchezBalibrea, J., ANd ERschbamer, B. (2017). The role of seed traits as segregation factors of hybrids in wild populations of Cistus (Cistaceae). Plant Biosystems An International Journal Dealing with All Aspects of Plant Biology, 151(3), 530-538. 
Nitsch, J. P., AND Nitsch, C. (1969). Haploid plants from pollen grains. Science, 163(3862), 85-87.

ÖNCEL, Z., AND ERIŞEN, S. (2017). Clonal propagation of jojoba by in vitro culture and determination of sexuality of the regenerants. Journal of Animal and Plant Sciences, 27(2), 567-574.

Ortiz, P. L. (1994). The Cistaceae as food resources for honey bees in SW Spain. Journal of Apicultural Research, 33(3), 136-144.

Ortuño, A., Díaz, L., Pérez, I., Sánchez, F., AND Del Río, J. A. (2018). Biological active compounds from Limonium insigne and alternative methods for its micropropagation. Scientia Horticulturae, 230, 78-85.

Ou, Y., Lü, J., Teixeira Da Silva, J. A., And Ma, G. (2015). Vegetative propagation of Metabriggsia ovalifolia W. T. Wang using leaf cuttings and petiole segments. The Journal of Horticultural Science and Biotechnology, 90(6), 724-727.

Papafotiou, M., Triandaphyllou, N., and Chronopoulos, J. (2000). Studies on propagation of species of the xerophytic vegetation of Greece with potential floricultural use. Acta Horticulturae, 541, 269-272.

Park, S.-H., Elhiti, M., Wang, H., Xu, A., Brown, D., AND WANG, A. (2017). Adventitious root formation of in vitro peach shoots is regulated by auxin and ethylene. Scientia Horticulturae, 226, 250-260.

Pela, Z., Pentcheva, M., Gerasopoulos, D., And Maloupa, E. (2000). In vitro induction of adventitious roots and proliferation of Cistus creticus creticus L. plants. Acta Horticulturae, 541, 317-322.

PreiL, W. (2003). Micropropagation of ornamental plants. In M. Laimer and W. Rücker (Eds.), Plant tissue culture (pp. 115-133). Vienna, Austria: Springer.

Rizzotтo, M. (1979). Ricerche tassonomiche e corologiche sulle Cistaceae. 1. Il genere Cistus L. in Italia. Webbia, 33(2), 343-378.

Rout, G. R., AND JAIN, S. M. (2004). Micropropagation of ornamental plants. Propagation of Ornamental Plants, 4(2), 3-28.

Ruta, C., And Morone-Fortunato, I. (2010). In vitro propagation of Cistus clusii Dunal, an endangered plant in Italy. In Vitro Cellular \& Developmental Biology-Plant, 46(2), 172-179.
Saia, S., Aissa, E., Luziatelli, F., Ruzzi, M., Colla, G., Ficca, A. G., Cardarelli, M., and Rouphael, Y. (2020). Growth-promoting bacteria and arbuscular mycorrhizal fungi differentially benefit tomato and corn depending upon the supplied form of phosphorus. Mycorrhiza, 30, 133-147, https://doi. org/10.1007/s00572-019-00927-w.

Said, M. E.-A., Militello, M., Saia, S., Settanni, L., Aleo, A., Mammina, C., Bombarda, I., Vanloot, P., Roussel, C., and Dupuy, N. (2016). Artemisia arborescens essential oil composition, enantiomeric distribution, and antimicrobial activity from different wild populations from the Mediterranean area. Chemistry \& Biodiversity, 13(8), 1095-1102.

Scuderi, D., Di Gregorio, R., Toscano, S., Cassaniti, C., AND Romano, D. (2010). Germination behaviour of four mediterranean Cistus L. species in relation to high temperature. Ecological Questions, 12-Speci, 175-186.

SEDLÁk, J., AND PAPRŠTEIN, F. (2011). Micropropagation of cranberry (Vaccinium macrocarpon) through shoot tip cultures - Short communication. Horticultural Science, 38(4), 159-162.

Silva, J., Rego, F., And Martins-Loução, M. (2002). Belowground traits of Mediterranean woody plants in a Portuguese Shrubland. Ecologia Mediterranea, 28(2), 5-13.

Silva, J. S., Rego, F. C., And Martins-Loução, M. (2003). Root distribution of Mediterranean woody plants. Introducing a new empirical model. Plant Biosystems, 137(1), 63-72.

Venkatasalam, E. P., Sharma, S., Pandey, K. K., Sharma, S., Thakur, V., Sood, R., and Singh, B. P. (2015). Influence of hermetic and nonhermetic culture rooms on biochemical and in vitro morphological characters of potato cultivars. Indian Journal of Horticulture, 72(3), 353.

Yoo, K.-R., And LeE, S.-Y. (2017). Effects of lightemitting diodes on in vitro growth of virus-free sweet potato plantlets. Horticultural Science \& Technology, 35(4), 490-498.

Zygomala, A. M., IoAnnidis, C., And Koropouli, X. (2003). In vitro propagation of Cistus creticus L. Acta Horticulturae, 616, 391-396.

Received April 11, 2019; accepted November 12, 2019 